\section{Estudo \\ Ecidebate}

em Testão

Plamejamento
Revista Estudo \& Debate, Lajeado, v. 26, n. 4, 2019. ISSN 1983-036X

DOI: http://dx.doi.org/10.22410/issn.1983-036X.v26i4a2019.2176

\title{
APROXIMAÇÓES TEÓRICAS SOBRE AGROECOLOGIA NAS PESQUISAS RELACIONADAS AS CIÊNCIAS HUMANAS
}

\author{
Luciana Turatti ${ }^{1}$, Vanessa Vilante ${ }^{2}$
}

\begin{abstract}
Resumo: O presente artigo tem por escopo apresentar os resultados de um estudo bibliométrico acerca das publicaçóes sobre agroecologia na área de ciências humanas, que tem como objetivo subsidiar a pesquisa desenvolvida na UNIVATES sobre os sentidos atribuídos a Política Nacional de Agroecologia (Decreto No 7.794 de 2012), por um Grupo de Agricultores Ecologistas do município de Arroio do Meio, RS, Brasil. Tratase de uma pesquisa quali-quantitativa que utilizou a bibliometria e a análise textual como principais ferramentas metodológicas. A análise bibliométrica contemplou artigos publicados nas bases de dados Scielo e CAPES referentes ao período de 2002 a 2016. Os resultados demonstram uma visáo uniforme acerca do tema quando do tratamento pelos diversos autores, um aumento expressivo das produçóes relacionadas à área a partir de 2010 e o forte vínculo das publicaçóes a pesquisas desenvolvidas em universidades públicas.
\end{abstract}

Palavras-chave: produção orgânica; metodologia participativa; percepçôes; políticas públicas.

\section{THEORETICAL APPROACHES ABOUT AGROECOLOGY IN RESEARCH RELATED TO THE HUMAN SCIENCES}

\begin{abstract}
The purpose of this paper is to present the results of a bibliometric study about the publications on agroecology in the human sciences, which aims to support the research developed in UNIVATES about the meanings attributed to the National Policy of Agroecology (Decree No. 7.794 of 2012), by a Group of Ecologist Farmers of Arroio do Meio, RS, Brazil. It is a qualitative-quantitative research that used bibliometrics and textual analysis as main methodological tools. The bibliometric analysis included articles published in the Scielo and CAPES databases for the period from 2002 to 2016. The results demonstrate a uniform view of the subject by the various authors investigated, a significant increase of the productions related to the area as of 2010 and the strong link of publications to research developed in public universities.
\end{abstract}

Keywords: organic production; participatory methodology; perceptions; public policy.

1 Doutora em Direito. Professora dos Programas de Pós Graduação em Ambiente e Desenvolvimento (PPGAD) e em Sistemas Ambientais Sustentáveis (PPGSAS) da Universidade do Vale do Taquari UNIVATES. E.mail: lucianat@univates.br.

2 Acadêmica do Curso de Comunicaçáo Social - Publicidade e Propaganda da Universidade do Vale do Taquari - UNIVATES. Bolsista de iniciação científica do Projeto Política Nacional de Política Nacional de Agroecologia e Produção Orgânica: a construção de sentidos acerca das diretrizes nacionais por grupos de agricultores ecologistas, RS, Brasil. E-mail: vanessa.vilante@univates.br 


\section{Notas iniciais}

A busca pela segurança alimentar e a ideia de superaçáo dos impactos de ordem ambiental ocasionados pelo modo de produção convencional têm impulsionado o consumo de alimentos orgânicos e, por consequência, tem legitimado aqueles que buscam realizar a transição do modelo convencional para o agroecológico, apesar de ainda predominarem no campo, sistemas que promovem o cultivo intensivo do solo, a monocultura, a irrigação, a aplicação de fertilizantes inorgânicos, o controle químico de pragas e a manipulação genética de plantas cultivadas.

O que se percebe após décadas de predomínio da agricultura tida como moderna, é que as teorias que geraram a ruptura com os meios tradicionais e embasaram a Revolução Verde contribuíram muito mais para uma crise socioambiental do que para a melhoria da vida no campo. As consequências deste modelo abriram espaços para novas indagaçóes e o resgate de uma agricultura mais tradicional, fundamentada nos saberes locais e conhecimentos tradicionais e na construção de relações harmônicas com a natureza. Frente a demanda por sistemas sustentáveis relacionados aos processos de produção de alimentos, em de 20 de agosto de 2012, foi publicado no Brasil o Decreto No 7.794, que estabelece a Política Nacional de Agroecologia e Produção Orgânica (PNAPO). Este decreto induz ao estreitamento dos conhecimentos das diversas áreas científicas com os saberes dos agricultores. Neste movimento, os agricultores deixam de ser meros objetos de estudo para se constituírem em sujeitos participantes da sistematização e concepção de novos conhecimentos.

Pautado em tais premissas, em 2016 foi proposta a pesquisa denominada "Política Nacional de Agroecologia e Produção Orgânica: a construção de sentidos entorno das diretrizes nacionais pelo Grupo de Agricultores Ecologistas de Forqueta, Arroio do Meio, RS, Brasil", que conta com apoio do CNPq por meio do Edital Universal. A proposta estabelece suas bases em metodologias participativas, sendo que a abordagem adotada é qualitativa.

O presente artigo apresenta os resultados da fase inicial da pesquisa, em especial do estudo bibliométrico realizado para amparar as análises, ainda em andamento, dos estudos de campo, como forma de se avaliar a influência dos pesquisadores ou periódicos, na área da agroecologia e traçar as tendências nas publicaçóes.

\section{Breve contextualização teórica}

A produção agroecológica cresceu consideravelmente ao longo das últimas décadas. Segundo dados divulgados pelo Ministério da Agricultura, Pecuária e Abastecimento brasileiro, a partir de um balanço feito pela Federação Internacional de Movimentos da Agricultura Orgânica (Ifoam) e divulgado em fevereiro de 2019, o mercado global de orgânicos, sob a liderança dos Estados Unidos, Alemanha, França e China, movimentou o volume recorde de US\$ 97 bilhóes no ano de 2017 (MAPA, texto digital). Estima-se que em torno de $20 \%$ do crescimento no consumo de alimentos por ano correspondem ao mercado de orgânicos, o qual já atinge mais de 130 países em todo o mundo (DIAS, et al., 2015). 
O plantio e mercado de produtos orgânicos também se coloca como uma alternativa aos meios de produção convencionais orientados pelo mercado neoliberal conservador (baseado na maximização da produção e eficiência econômica) e classificados como dilapidadores dos recursos naturais, vez que associados a problemas sociais e ambientais.

Tais meios, surgidos ainda no início do século XVIII com a teoria de Justus Liebig (1803-73) e alimentados por outras teorias que a sucederam, também serviram de fundamento para a promoção da Revolução Verde, que, segundo Caporal e Costabeber (2002, p. 10) elevou a produtividade somente nas propriedades e regióes que já gozavam de renda elevada, ampliando, por consequência a exclusão e as desigualdades sociais.

A insustentabilidade do modelo proposto pelas teorias que influenciaram o paradigma hegemônico na agricultura, abriram espaço para novos questionamentos e o retorno das ideias de uma agricultura mais tradicional. Um alerta foi dado acerca do esgotamento promovido pelos meios de produção orientados pela Revolução Verde, com a publicação da obra Blueprint for survival, de Dennis e Donella Meadows. No entanto, foi somente a partir da instalação de algumas crises sanitárias ligadas a bactérias e vírus que infectaram animais, como se deu com o famoso caso da doença da "vaca louca" na década de 80 que ocorreu, na Europa, a retomada das discussóes envolvendo a agroecologia e a agricultura orgânica. A partir disto, movimentos de agricultura alternativos ao convencional que buscavam combater a aplicação abusiva de insumos químicos e defendiam o retorno dos conhecimentos tradicionais voltaram ao cenário nacional e internacional, vez que passaram a ter um reconhecimento cada vez maior (DIAS, et al, 2015).

Além disso, como forma de se atingir a sustentabilidade e a autoregulaçáo dos agroecossistemas, "a agroecologia não só enfatiza a importância dos parâmetros agronômicos e ecológicos, como também das questóes socioeconômicas, resgatando o fato de que a agricultura, além de ser um processo ecológico, é um processo social" (ASSIS, 2006, p. 77). É em decorrência desta preocupação que práticas e questóes sociais e éticas, tais como, práticas trabalhistas justas, agricultura familiar, viabilidade ética e animal passaram a compor os princípios orientadores da agricultura orgânica (DIAS, et al, 2015).

Como forma de dar consecução a estes propósitos em 2012 foi publicado no Brasil o Decreto No 7.794 que institui a Política Nacional de Agroecologia e Produção Orgânica (PNAPO). No artigo $3^{\circ}$ do decreto foram constituídas as diretrizes da PNAPO, das quais destacam-se o direito humano à alimentação adequada e saudável, por meio da oferta de produtos orgânicos e de base agroecológica isentos de contaminantes que ponham em risco a saúde (I) e a promoção de sistemas justos e sustentáveis de produção, distribuição e consumo de alimentos (IV).

É possível perceber quando da leitura destas diretrizes uma grande aproximação dos princípios orientadores da agroecologia, a qual, segundo Caporal e Azevedo (2011) busca integrar e considerar os saberes dos agricultores construídos ao longo da história com os conhecimentos de diferentes ciências, permitindo, por consequência, uma crítica ao atual modelo de desenvolvimento agrícola, tido como hegemônico, e a propositura de novas estratégias de desenvolvimento rural, pautadas por formas mais sustentáveis de produção e por uma abordagem transdisciplinar e holística. 
Ocorre que a simples propositura de uma Política não é capaz, por si só, de gerar efeitos imediatos no mundo dos fatos. O primeiro desafio que se impóe após sua publicação, de forma a torná-la efetiva, diz respeito ao conhecimento do seu texto por parte daqueles diretamente implicados. Outrossim, o cenário brasileiro tem demonstrado, ao longo da história, que muitas leis são publicadas sem considerar os anseios dos destinatários ou ainda à revelia destes, refletindo somente a vontade de uma minoria, e isto motivado, em parte, pela baixa participação popular nos processos decisórios. Outro fator que dificulta a aplicação das leis está vinculado ao uso de um linguajar essencialmente jurídico com característica notadamente técnica e, muitas vezes, de difícil compreensão por uma grande parcela da população, tornando ainda mais penoso o seu conhecimento e consequente aplicação. Tal fato apresenta um paradoxo, uma vez que a própria lei (art. $3^{\circ}$ da Lei de Introduçáo às Normas do Direito Brasileiro) determina que ninguém pode alegar o desconhecimento de lei.

Ainda, há de se ter presente, que a aplicação das leis não pode se voltar a mera reproduçáo das regras previstas nos textos normativos. Orientada pelos princípios constitucionais, esta deve ser capaz de considerar a complexidade existente entorno do tema, bem como a soberania popular. Enfim, este é o sentido que a interpretação da legislação deve assumir e é neste contexto que em 2016 foi proposta a pesquisa denominada "Política Nacional de Política Nacional de Agroecologia e Produção Orgânica: a construção de sentidos acerca das diretrizes nacionais por grupos de agricultores ecologistas, RS, Brasil" desenvolvida na Universidade do Vale do Taquari - UNIVATES.

Com o objetivo de investigar os sentidos atribuídos à Política Nacional de Agroecologia e Produção Orgânica por um grupo específico, foram propostos os seguintes questionamentos como problema de pesquisa: Que sentidos (sociais, econômicos, ambientais e culturais) o Grupo de Agricultores Ecologistas do Forqueta atribui às diretrizes da Política Nacional de Agroecologia e Produção Orgânica? Que elementos emergem desta construção de sentidos? O modelo de produção adotado por este Grupo observa as diretrizes propostas? Quais são as estratégias sustentáveis existentes?

A escolha do Grupo de Agricultores Ecologistas do Forqueta, localizado no município de Arroio do Meio, RS, ocorreu por proximidade e também pelo fato deste se constituir, na atualidade em um grupo organizado e consolidado na região do Vale do Taquari desde 2000, tendo encontrado na agroecologia um locus de produção mais sustentável e não somente uma forma alternativa de agricultura. Por fim, ainda se faz importante referir que este grupo compóe o coletivo denominado Articulação de Agroecologia para o Vale do Taquari o que demonstra a possibilidade de espraiamento da proposta aqui sustentada.

Para se alcançar o objetivo pretendido a pesquisa iniciou pela identificação do estado da arte. Para isso, procedeu-se um estudo bibliométrico voltado para identificação das pesquisas existentes nas plataformas CAPES e SCIELO que relacionavam-se a área de ciências humanas e que tivessem conexão com os propósitos da pesquisa. Feitas as triagens necessárias foram selecionados os artigos que compóem os resultados apresentados neste artigo. 


\section{Metodologia}

$\mathrm{O}$ estudo caracteriza-se como uma pesquisa quali-quantitativa que utilizou a bibliometria e a análise textual como principais ferramentas metodológicas.

A análise bibliométrica teve início em maio de 2016, oportunidade na qual foram consultados os portais Capes (Comissão de Aperfeiçoamento de Pessoal do Nível Superior) com 780 resultados entre artigos e periódicos, e Scielo (Scientific Electronic Library Online) com 124. Os termos aplicados no sistema de busca livre foram: "agroecologia", sendo a expressão utilizada de forma isolada e, num segundo momento: "legislação e agroecologia", tendo sido consideradas as obras publicadas no período de 2002 a 2016. Considerando o número de artigos identificado nos resultados (904 artigos), procedeu-se uma nova triagem, desta vez, aplicando-se aos artigos selecionados expressóes que os aproximassem dos objetivos da pesquisa em andamento, sendo eles: sentido; legislação; direito; informação; comunicação; sistemas ambientais; publicidade das informações; produção da informação, alcançando-se ao final um total de 36 artigos.

A coleta de dados consistiu na quantificação de elementos presentes nos artigos identificados, na qual foram considerados: os temas que vem pautando os artigos escritos, identificados a partir do conteúdo dos títulos e resumos; os vínculos profissionais dos autores (se pertencentes às Universidades Públicas ou Privadas); o qualis (utilizou-se como referência o qualis a época definido no sistema webqualis como 2014, na área interdisciplinar, uma vez que a pesquisa está vinculada a um Programa de Pós Graduação nesta área) das revistas que têm publicado artigos relacionados à agroecologia; o ano de publicação dos artigos; as palavras-chave utilizadas; as regióes as quais se vinculam os autores; bem como os referenciais mais utilizados quando da construção das ideias sobre agroecologia.

Ao final ainda foi realizada uma leitura atenta de todos os artigos, valendo-se para tanto da análise textual proposta por Moraes (2015), com o objetivo de se evidenciar as aproximações realizadas pelos diversos autores e ainda as contribuições que estes poderiam apontar para o tema.

\section{Resultados e discussóes}

A primeira parte da investigação envolveu a análise dos títulos e resumos, de onde foram extraídas as palavras-chave e agrupadas por categorias como forma de verificar a recorrência ou inovação em torno dos assuntos envolvendo a agroecologia. Cabe ressaltar que alguns resumos foram enquadrados em mais de uma categoria.

Os artigos que versavam sobre práticas agroecológicas (03) se propunham a discutir uma agricultura voltada ao autoconsumo alimentar e a orientação encontrada nos princípios agroecológicos. Aqueles que tratavam do desenvolvimento da agroecologia (06) contemplavam essencialmente a evolução histórica e o resgate à tradição propagada pelos agricultores agroecológicos. Já os que discutiam a ideia de sustentabilidade (06) faziam associaçóes entre a agroecologia e o consumo sustentável; ou tratavam do próprio desenvolvimento sustentável.

Os artigos que discorriam sobre a certificação (01) abordavam as diversas formas de certificação, dentre as quais a solidária. Aqueles com caráter mais teórico (10), traziam temas 
como a demanda de uma epistemologia especial para agroecologia; o cuidado metodológico com a definiçáo dos agroecossistemas; a ontologia da agricultura; a evolução das ciências agrárias e o papel da inovação; as bases conceituais da agroecologia; o estudo das bases epistemológicas da agroecologia; e a desmistificação da agroecologia.

Os estudos que se propunham a dialogar sobre as questôes políticas (03), realizavam uma análise das condiçôes, das instituiçóes e dos conflitos sociais que resultam do apoio a uma transição agroecológica; demandas de políticas públicas para a implementação de um processo de desenvolvimento rural sustentável, com base na ação local, que tenha como fundamento sistemas de produção agroecológicos; políticas públicas e desenvolvimento social rural.

A publicação que versava sobre as diferentes formas de construção do espaço rural transitava sobre distintas formas de construção do espaço rural, por meio da agricultura familiar, agroecologia e pluriatividade. Na forma de Estudos de Caso, foram publicadas 08 análises envolvendo situaçóes práticas que contemplavam a agroecologia; ou ainda a abordagem de um método de investigação participativa; e até mesmo situaçóes bem pontuais como o movimento agroecológico no Chile. Os estudos sobre redes (02) traziam apontamentos sobre as distintas redes de conhecimento que se cruzam no rural brasileiro se interconectam e interagem; e o exame das açóes de agricultores ligados a rede de agroecologia.

A análise envolvendo a propriedade intelectual se propôs a investigar o panorama da propriedade intelectual sobre a biodiversidade e a produção de conhecimentos. Já os artigos que tratavam da introdução à agroecologia (02) buscavam iniciar o leitor nas bases conceituais e metodológicas da agroecologia e discorriam sobre a relevância da agroecologia e a crescente importância da produção dos alimentos. Ainda foram identificados 04 artigos que propunham relaçôes entre a agricultora ecológica e a produção orgânica.

Segundo a verificação realizada a maior parte dos artigos volta-se a discussão teórica do tema, recebendo destaque os discursos em busca da identificação ou construção de uma base epistemológica para agroecologia e aqueles voltados para constituiçấo das bases conceituais. Apontam-se assim espaços para futuras pesquisas, visto que, firmar as bases epistemológicas que compóem os princípios da agroecologia constitui-se uma premissa para evolução da área.

Num segundo momento foram avaliadas as palavras-chave utilizadas nos artigos investigados, que demonstra uma disseminação de temas entorno da questáo central que é a agroecologia (Quadro 1). Poucas palavras-chave se repetiram. Foi o caso, por exemplo, da "agricultura familiar" e "sustentabilidade" que apareceram em maior número. Percebese com isso que o tema agroecologia é de fato transversal e se conecta com diferentes áreas de conhecimento, mesmo que a escolha dos artigos tenha sido pautada por temas essencialmente vinculados às ciências humanas. Por outro lado, a presença de várias palavraschave pode demonstrar uma pulverizaçáo dos conteúdos e a falta de uma visão uniforme sobre a temática. 
Quadro 1. Análise de conteúdo das palavras-chave indicadas nos artigos coletados na meta-análise

\begin{tabular}{|c|c|}
\hline Palavras-chave & Quantidade \\
\hline Agroecologia & 25 \\
\hline Agricultura familiar & 5 \\
\hline Sustentabilidade & 5 \\
\hline Transdisciplinaridade & 3 \\
\hline Agricultura Orgânica & 3 \\
\hline Agricultura alternativa & 3 \\
\hline Sistemas Complexos & 2 \\
\hline Território e territorialidade & 2 \\
\hline Práticas agroecológicas & 2 \\
\hline Epistemologia & 2 \\
\hline Pensamento Complexo & 2 \\
\hline Transição agroecológica & 2 \\
\hline Desenvolvimento Rural & 2 \\
\hline Investigação Participativa & 2 \\
\hline Epistemologia da Agroecologia & 2 \\
\hline Interdisciplinaridade & 2 \\
\hline Mercado orgânico & 2 \\
\hline Modernização conservadora da agricultura & 1 \\
\hline Pluriatividade & 1 \\
\hline Espaço rural & 1 \\
\hline Agricultura camponesa & 1 \\
\hline Certificaçáo social & 1 \\
\hline Crise Socioambiental & 1 \\
\hline Desenvolvimento Rural Sustentável & 1 \\
\hline Mudança Social & 1 \\
\hline Política de Agroecologia & 1 \\
\hline Campesinato & 1 \\
\hline Movimentos Sociais & 1 \\
\hline Convencionalização & 1 \\
\hline Co-evolução & 1 \\
\hline Agroecossistema & 1 \\
\hline História da agricultura & 1 \\
\hline Comunismo & 1 \\
\hline Educação Ambiental & 1 \\
\hline Comunidade de aprendizagem & 1 \\
\hline Eficiência & 1 \\
\hline SPF - Stochastic production frontier & 1 \\
\hline Representaçóes Sociais & 1 \\
\hline Paradigma Científico Convencional & 1 \\
\hline Pluralismo & 1 \\
\hline Metodológico & 1 \\
\hline Filosofia Ambiental & 1 \\
\hline Ética ambiental & 1 \\
\hline
\end{tabular}




\begin{tabular}{|c|c|}
\hline Palavras-chave & Quantidade \\
\hline Teoria de estudos rurais & 1 \\
\hline Agronomia & 1 \\
\hline Soberania e segurança alimentar & 1 \\
\hline Inovação & 1 \\
\hline Tecnologia & 1 \\
\hline Organização social camponesa & 1 \\
\hline Autogestão & 1 \\
\hline Poder local & 1 \\
\hline Autonomia & 1 \\
\hline Tomada de decisóes & 1 \\
\hline Ciência pós-normal & 1 \\
\hline Investigação Agricultura & 1 \\
\hline Conhecimento local camponês e indígena & 1 \\
\hline Sistemas & 1 \\
\hline Mitos & 1 \\
\hline Discurso & 1 \\
\hline Meio ambiente & 1 \\
\hline Produção & 1 \\
\hline Cooperativas & 1 \\
\hline Coletivo & 1 \\
\hline Política Pública & 1 \\
\hline Reforma agrária & 1 \\
\hline Autoconsumo & 1 \\
\hline Desenvolvimento & 1 \\
\hline Aprendizado híbrido & 1 \\
\hline Comunicação & 1 \\
\hline Informática & 1 \\
\hline Redes & 1 \\
\hline Conhecimento & 1 \\
\hline Modernidade & 1 \\
\hline Sementes da Paixão & 1 \\
\hline Invenção das tradições & 1 \\
\hline Propriedade intelectual & 1 \\
\hline Multiplicidade & 1 \\
\hline Conflitos ambientais & 1 \\
\hline Biodemocracia & 1 \\
\hline Alimentos orgânicos e agricultura & 1 \\
\hline Análise comparativa & 1 \\
\hline
\end{tabular}

Percebe-se que a partir do ano de 2011 houve um aumento do número de artigos envolvendo agroecologia em revistas científicas (Figura 1). A queda brusca no número de publicaçóes no ano de 2014 foi vista como um momento isolado, não podendo servir de orientação geral. Também porque no ano seguinte houve novamente um grande salto nas publicaçóes. 
Figura 1. Ano de publicações dos artigos selecionados

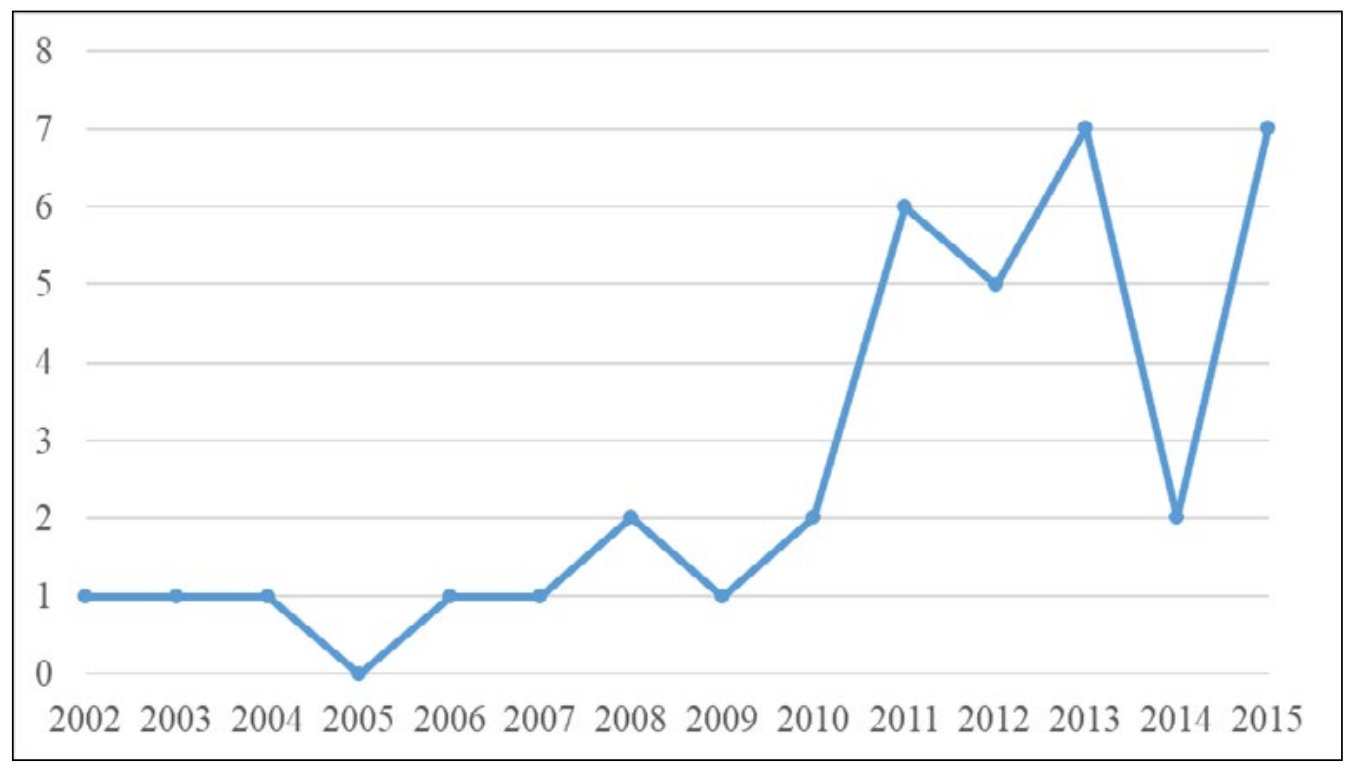

Considerando que o Qualis ainda se coloca, na atualidade, como um indexador importante para fins de classificação das publicações e ainda para avaliação dos diversos programas de pós-graduação e dos próprios docentes dos programas, entendeu-se que seria relevante identificar se o tema agroecologia vem angariando espaço nas revistas de extrato superior (como por exemplo, A1 e A2). A maior parte dos artigos publicados náo atingiu os extratos superiores, sendo publicados em revistas B1 e B2 na sua maioria ou, ainda, em revistas não indexadas (Quadro 2). Isto pode denotar que o tema ainda não galgou espaços em revistas melhor indexadas ou a existência de poucas revistas com escopo voltado para agroecologia.

Quadro 2. Revistas em que os artigos foram publicados e sua classificação segundo do indexador Qualis

\begin{tabular}{|l|c|c|}
\hline \multicolumn{1}{|c|}{ Revista } & $\begin{array}{c}\text { Qualis 2014 na área } \\
\text { Interdisciplinar }\end{array}$ & Quantidade \\
\hline Cuadernos de Desarrollo Rural & B1 & 2 \\
\hline Mercator & B2 & 1 \\
\hline Espaço Acadêmico & B4 & 1 \\
\hline Interciência (Caracas) & B1 & 1 \\
\hline (REC) Revista de Economia Critica & Sem indexaçáo & 1 \\
\hline Agroalimentaria & B2 & 1 \\
\hline Convergências & Sem indexaçấo & 1 \\
\hline Geografia Ensino \& Pesquisa (UFSM) & Sem indexaçẫo & 1 \\
\hline Desenvolvimento e Meio Ambiente & Sem indexação & 3 \\
\hline Educaçáo e Pesquisa & Sem indexaçấo & 1 \\
\hline
\end{tabular}




\begin{tabular}{|c|c|c|}
\hline Revista & $\begin{array}{l}\text { Qualis } 2014 \text { na área } \\
\text { Interdisciplinar }\end{array}$ & Quantidade \\
\hline REVIBEC & $\mathrm{B} 2$ & 1 \\
\hline Desenvolvimento em Questão & B2 & 1 \\
\hline Entramada & Sem indexação & 1 \\
\hline Cadernos de Ciência \& Tecnologia, Brasília & B3 & 2 \\
\hline Polis & Sem indexação & 1 \\
\hline Ciencia e Investigacíon Agraria & Sem indexação & 1 \\
\hline Luna Azul & Sem indexação & 2 \\
\hline Política y Sociedad & Sem indexação & 1 \\
\hline Agrociência & $\mathrm{B} 1$ & 1 \\
\hline Caderno de Agroecologia & Sem indexação & 1 \\
\hline Ambiência Guarapuava & $\mathrm{B} 2$ & 1 \\
\hline Cayapa & B3 & 1 \\
\hline RESR & Sem indexação & 2 \\
\hline INTERthesis & B2 & 1 \\
\hline Anthropologica & Sem indexação & 1 \\
\hline ISOFAR & Sem indexação & 1 \\
\hline Estudos Avançados & Sem indexação & 1 \\
\hline Ecossistemas & Sem indexação & 1 \\
\hline Economia aplicada & $\mathrm{B} 1$ & 1 \\
\hline São Paulo em Perspectiva & Sem indexaçáo & 1 \\
\hline $\begin{array}{l}\text { Não identificada (o artigo náo apresentava o nome da } \\
\text { revista) }\end{array}$ & & 1 \\
\hline
\end{tabular}

$\mathrm{O}$ enquadramento final dos artigos segundo o sistema qualis resultou no seguinte: nenhum artigo foi publicado em extratos A1 ou A2; 04 artigos foram publicados em extrato B1; 06 artigos foram publicados em extrato B2; 03 artigos em B3; 01 artigo em B4 e 22 artigos em revistas não indexadas.

A proposta de análise das instituiçóes aos quais os autores são vinculados teve como objetivo verificar se estes eram pertencentes às Universidades Públicas ou Privadas, para identificar o locus de desenvolvimento das pesquisas e a origem do apoio orçamentário para as pesquisas sobre agroecologia. O resultado apresentado no Quadro 3 demonstrou que as instituiçôes públicas têm fomentado mais as pesquisas sobre o tema. Somente 03 das instituições citadas são privadas. Cabe ressaltar que alguns autores possuem mais de um vínculo institucional.

Quadro 3. Instituiçôes as quais os autores são vinculados

\begin{tabular}{|l|c|}
\hline \multicolumn{1}{|c|}{ Instituiçóes } & Número de autores vinculados* \\
\hline Universidade Federal de Sergipe (UFS) & 1 \\
\hline Universidade Estadual do Oeste do Paraná (Unioeste) & 4 \\
\hline Universidade Federal de Pelotas (UFPEL) & 4 \\
\hline FATEC-Itapetininga & 1 \\
\hline Universidade Estadual Paulista & 1 \\
\hline
\end{tabular}




\begin{tabular}{|c|c|}
\hline Instituiçôes & Número de autores vinculados* \\
\hline ISEC-Universidad de Córdoba & 3 \\
\hline Universidad de Sevilla & 1 \\
\hline Universidad de Concepcíon & 1 \\
\hline Universidad Autónoma del Estado de México & 3 \\
\hline Universidade Federal de Santa Maria (UFSM) & 2 \\
\hline Emater/RS & 1 \\
\hline Embrapa & 7 \\
\hline Universidade Estadual de Campinas (UNICAMPI) & 2 \\
\hline Universidade de Brasília (UnB) & 1 \\
\hline University of Cambridge & 1 \\
\hline Universidade Estadual de Maringá (UEM) & 1 \\
\hline Universidad Nacional de Colombia & 1 \\
\hline Universidad Autónoma Chapingo & 1 \\
\hline Universidad Técnica de Babahoyo (UTB) & 1 \\
\hline Univarsidad de Caldas & 1 \\
\hline Universidad de los Llanos (Unillanos) & 1 \\
\hline Universidad de Antioquia & 4 \\
\hline Universidade Tecnológica Federal do Paraná (UTFPR) & 1 \\
\hline Centro Universitário Curitiba (UNICURITIBA) & 1 \\
\hline Centro Universitário FAE & 1 \\
\hline Universidade Federal do Paraná (UFPR) & 2 \\
\hline Universidade Federal de São Carlos (UFSCAR) & 1 \\
\hline Epagri & 1 \\
\hline Universidade Federal de Santa Catarina (UFSC) & 2 \\
\hline Universidade Federal do Pará (UFPA) & 1 \\
\hline Unidade de Ecodesenvolvimento INRA & 1 \\
\hline Instituto Agronômico do Paraná (IAPAR) & 1 \\
\hline Universidade Federal de Campina Grande (UFCG) & 2 \\
\hline Universidade Federal do Rio Grande do Sul (UFRGS) & 3 \\
\hline L'Institut national de la recherche agronomique (INRA) & 3 \\
\hline Swarthmore College & 1 \\
\hline Universitat de Barcelona & 1 \\
\hline UNESP & 1 \\
\hline TOTAL & 66 \\
\hline
\end{tabular}

Feita a verificação dos vínculos institucionais realizou-se a divisão dos autores por regióes geográficas, sendo que 24 autores se encontravam na região Sul; 01 na regiâo Norte; 03 no Nordeste; 07 no Centro-Oeste e 07 na região Sudeste, demonstrando com isso que a maior parte das produçóes tem origem na regiáo Sul. Esta informação pode estar associada a forte presença da agricultura familiar nesta região e a expressiva representação da agricultura ecológica neste território, visto que, segundo consulta as bases do Cadastro Nacional 
de Produtores Orgânicos em 28 de fevereiro de 2018, o RS possuía 2.271 agricultores cadastrados, SC possui 1224 e o Paraná, 2408. Somados, os três estados possuíam 5.903 o que representava $34 \%$ do total de 17.354 produtores existentes no país (MAPA, 2018).

A análise dos artigos também permitiu a realização de várias aproximaçóes entre os escritos dos autores, demonstrando com isso, uma certa recorrência por parte destes quando do tratamento do tema. Tal situaçáo pode estar vinculada as matrizes teóricas por estes utilizadas.

Neste sentido, faz-se necessário salientar que os autores mais utilizados na construção dos referenciais são Miguel Altieri - que é o mais citado - e Francisco Caporal (segundo mais citado). Na sequência aparecem José Antônio Costabeber, Stephen R. Gliessmann e Eduardo Sevilla Guzmán. Depois, de forma expressiva ainda são utilizados, Bellows Junior, Marcos Aurélio Saquet e Renato Linhares de Assis. Já em menor número aparecem Ángel Calle Collado, Giuseppe Dematteis, Maristela Simóes do Carmo, Karl Marx, Edgar Morin e Jan Douwe Van der Ploeg.

As produçóes convergem no sentido de reconhecer a expansão do setor orgânico no Brasil e apontam que esta pode representar uma alavanca para emancipação social de pequenos agricultores familiares, desde que, contudo, do outro lado da cadeia encontrem-se consumidores comprometidos e ocorra o fortalecimento das redes de agricultores por meio da integração (SANTOS e CHALUB-MARTINS, 2012).

Conforme Vargas, Fontoura e Wizniewsky (2013) a prática agrícola com base ecológica contribui para o restabelecimento do balanço energético de determinação do sistema, através do manejo sustentável dos sistemas de produção e da preservação da biodiversidade natural.

No que tange as premissas que compóem o enfoque agroecológico Caporal é utilizado como a principal referência. Citado por Barboza et. al. (2012) as premissas por ele estabelecidas são:

a) Atendimento aos requisitos sociais, como o bem-estar dos sujeitos implicados nas relações de trabalho;

b) Consideração dos aspectos culturais, por meio da valorização dos saberes locais, conhecimentos e valores dos diferentes grupos sociais;

c) Preservação dos recursos naturais e a consequente manutenção ou ampliação da biodiversidade;

d) Fortalecimento dos modelos associativos e das ações coletivas, com a efetiva participação dos envolvidos;

e) Empoderamento dos atores sociais e promoção da autogestão;

f) Obtenção de resultados econômicos a partir de uma relação entre a produção e a preservação dos recursos naturais;

g) Observância dos requisitos éticos e o compromisso com uma sociedade justa, igualitária e fraterna. 
Somam-se a estas segundo Saquet (2014): a) a conservação das águas, das plantas e dos animais; b) o aumento da capacidade de uso múltiplo do território; c) a reciclagem de nutrientes e da matéria orgânica; d) a preservaçáo das identidades culturais, valorizando o conhecimento dos agricultores, sua participação nos processos decisórios e favorecendo o uso eficaz dos recursos de cada unidade produtiva; e, e) o controle biológico de pragas. Cabe lembrar que a lista proposta por Saquet recebeu influência de autores como Altieri, Caporal, Costabeber, Gliessman e Toledo, por ele citados.

Num cenário semelhante Duval, Ferrante e Valencio (2008), também influenciados por Caporal e Costabeber (2003), ao defenderem uma proposta de agricultura sustentável estabelecem o que denominam de princípios agroecológicos, dentre os quais destacam-se: a menor dependência de insumos comerciais e maior uso de recursos disponíveis localmente; uso das diversas interaçôes (ecológicas, biológicas, químicas e físicas) que ocorrem no local em benefício produtivo; intenção de beneficiar a propriedade como um todo, e não a um produto específico; aceitação e/ou convivência com as condiçóes ecológicas locais antes da tentativa de controle sobre o meio ambienta; preservaçáo da diversidade biológica e cultural; uso do conhecimento tradicional; dentre outras.

Santos e Chalub-Martins (2012) abordam as bases da agroecologia quando defendem que este movimento se pauta pela proposta de construção de coletivos onde reúnamse indivíduos com histórias de vida diferentes e motivaçôes diversas, que, no entanto, compartilhem de um interesse comum.

Dando sequência, Santos e Chalub-Martins (2012) também citam os avanços epistemológicos relacionados aos processos educacionais que visam problematizar o contexto socioambiental em que a sociedade está inserida. Para tanto, relembram os principais avanços epistemológicos na área educacional citando: a educaçáo popular, a ecopedagogia, a justiça ambiental, e a emancipação dos sujeitos.

Os artigos também exaltam a importância do conhecimento endêmico e a manutenção de técnicas por parte dos agricultores ecologistas, o que configura os chamados saberes locais. Neste sentido, também são lembrados os movimentos de transmissáo e guarda das sementes crioulas e das variedades de cultivo local. Alves e Guivant (2010) relacionam estas questôes a ideia de participação, defendendo que o eixo central da agroecologia gira em torno da valorizaçáo do conhecimento local e da participação dos agricultores em todos os processos como agentes principais de desenvolvimento.

Como barreiras para produção de orgânicos, o estudo de caso apresentando por Santos e Chalub-Martins (2012) referiu as dificuldades relacionadas à logística para alcançar os mercados, que é considerada onerosa, e o consumo náo consciente, ou massificado, e influenciado pelo aporte publicitário.

O artigo de Alves e Guivant (2010) também apresenta contribuições significativas para constituição do estado da arte pois expóe o design da evolução das experiências agroecológicas, iniciando com um quadro no qual pontua os principais modelos de desenvolvimento e paradigmas dominantes de 1950 a 2000; passando para outro acerca dos modelos de desenvolvimento rural e apresentando ao final o quadro com as principais formas 
de agricultura sustentável, quais sejam: a agricultura orgânica; a agricultura biodinâmica; a agricultura natural; a agricultura biológica, e a agricultura ecológica.

Os autores (2010) também abordam a importância das redes para o desenvolvimento da agricultura sustentável e abordam a constituição de certificadoras de alimentos e a consequente necessidade da criação de sistemas de confiança, articulados não somente com as dimensóes territoriais internas mas que também dialoguem com os consumidores de orgânicos, além de influenciar e articular um discurso legal, institucional e cientifico.

Apontam ainda que as soluçóes inovadoras, portanto, não estão ligadas somente ao progresso tecnológico, mas também a busca de novos métodos de organização e administração envolvendo processos e informaçóes.

Fernandes e Pascual (2015) apoiando-se nas ideias de Lowrance et al., 1986; Conway e Barbier, 1990, e Gliessman, 1997, lembram ainda que não há como dissociar a agroecologia da necessidade de produção. Os autores entendem que para ser sustentável a agricultura deve ser também altamente produtiva, para atender a demanda de alimentos e fibras da sociedade. Com o objetivo de analisar a eficiência da agricultura familiar agroecologista o autor apresenta conclusóes importantes: a tomada de crédito contribui para ineficiência; o aumento do número de pessoas trabalhando na unidade familiar aumenta a eficiência, em decorrência do aumento na quantidade de capital humano disponível; e, que o aumento da escolaridade também aumenta a eficiência, em decorrência do aumento da qualidade do capital humano.

Canuto (2011) aponta, neste sentido, que nos sistemas agroecológicos a rentabilidade econômica está fortemente vinculada aos baixos custos de produçáo, devido ao emprego de poucos insumos. Os insumos basicamente se resumem a aquisição de mudas ou sementes, água e trabalho.

Em outro cenário, Saquet (2014) estabelece algumas aproximações entre a agricultura camponesa e a agricultura agroecológica, dizendo que as práticas (agro)ecológicas concretizam-se como uma práxis da agricultura camponesa diferenciada, segundo apontam Altieri (1998, 2012); Gliessman (2000) e Guzmán e Molina (2005).

$\mathrm{O}$ autor refere ainda que os principais referenciais da agricultura camponesa são Karl Marx, Alexander Chayanov, Teodor Shanin, José de Moura Martins, José Vicente Tavares dos Santos e Ariovaldo Umbelino de Oliveira.

$\mathrm{Na}$ agricultura camponesa, os camponeses tem um forte vínculo com a terra, constroem um sentimento de pertencimento a um grupo ou local; têm como objetivo principal a reprodução biológica e social da família e não a valorização e acumulação de capital; tem uma íntima relação entre trabalho familiar e consumo da família; integração ao mercado via circulação de mercadorias, mas não há uma produção intensiva; mecanismo de preços diferenciado do mercado; predomínio do trabalho familiar; compartilhamento de conhecimentos e práticas produtivas; entre outros. Como se vê muitos destes preceitos tem forte vinculação aos princípios orientadores da agroecologia (SAQUET, 2014).

Borsato e do Carmo (2012, p. 711 e 712) também apresentam um aporte significativo quando tratam de questóes epistemológicas, lembrando que "a agroecologia emerge 
no campo científico como uma resposta à crise socioambiental que o mundo rural vem atravessando, para a qual as disciplinas convencionais não conseguem encontrar respostas".

Segundo estes autores, a abertura epistemológica ocorreria com a introdução dos saberes camponeses na ciência; e a valorização do conhecimento local a ponto de colocá-lo em pé de igualdade com o conhecimento científico, aquilo que Leff denomina de diálogo de saberes.

E é dentro deste contexto que os autores apresentam como conceito de agroecologia, aquele proposto por Sevilla Guzmán em 2006:

\begin{abstract}
definimos la Agroecología como el manejo ecológico de los recursos naturales a través de formas de acción colectiva para ele establecimiento de sistemas de control participativo y democrático, en los âmbitos de la producción y circulación. La estratégia teórica y metodológica así elaborada tendrá, además; por un lado, una naturaliza sistémica y un enfoque holístico, ya que tales formas de manejo habrán de frenar selectivamente el desarrollo actual de las fuerzas productivas para contener las formas degradantes de producción y consumo que han generado la crisis ecológica. Y, por outro lado, tal necessário manejo ecológico de los recursos naturales, tendrá igualmente, una flerte dimensión local como portadora de un potencial endógeno, que, a través del conocimiento campesino (local o indígena, allá donde pueda aun existir), permita la potenciación de la biodiversidade ecológica y sociocultural y el diseño de sistemas de agricultura sostenible" (BORSATO e CARMO, 2012).
\end{abstract}

Por fim, Canuto (2011) consegue resumir o que seria a perspectiva ideológica da agroecologia: a busca de uma nova ética política, a retomada de uma economia com rosto humano, o respeito pelo planeta, a convivência harmônica entre o homem e a natureza.

As políticas públicas aparecem como soluções aos problemas enfrentados em inúmeras passagens de artigos. Gehlen (2004, p. 102) no artigo intitulado "políticas Públicas e desenvolvimento social rural" sugere a disseminação das políticas públicas como forma de fortalecer o desenvolvimento local, visto por eles como o resultado da "potencialização da participação dos beneficiários, através de iniciativas comunitárias, promovendo parcerias com o Estado (nos três níveis) e com empresas privadas” (GEHLEN, 2004, p. 102).

Assis (2003) já tratava do assunto em 2003 quando em seu artigo acerca da agricultura orgânica mencionava que uma das dificuldades existentes para os agricultores familiares dizia respeito ao acesso a informaçóes e as formas de organização. Passados 15 anos acreditase que o acesso à informação ainda não foi devidamente efetivado! Como forma de superar tais dificuldades o autor apontava a necessidade do Poder Público desenvolver políticas específicas, capazes de absorver as reais necessidades dos agricultores ecologistas.

Duval, Ferrante e Valencio (2008) enfatizam a necessidade de programas municipais que priorizem as necessidades e preferencias das famílias locais e promovam a venda direta (feiras, quitandas, supermercados, restaurantes...) e a utilização destes alimentos em projetos locais, como forma de contribuir para soberania alimentar.

Em outro momento Assis (2006) propõe que as políticas públicas sejam desenvolvidas junto as diferentes hierarquias (federal, estadual e municipal) e que se destinem 
especificamente as áreas de crédito, pesquisa e extensão, busquem abrir mercados, fomentar a produção e apoiem a organização autônoma de agricultores familiares.

Como reforça Souza (2011, p. 247), “a eficiência da agricultura tradicional está na capacidade de produzir sustentabilidade econômica, produtiva e ambiental sem necessário estar inserida na dependência dos instrumentos produtivos do capitalismo".

Acerca dos métodos utilizados nas pesquisas na área da agroecologia, os autores lembram que os agricultores não devem ser tratados como objeto de pesquisa, mas sim, como sujeitos participantes que contribuem para sistematização das experiências vivenciadas. E é dentro deste contexto que as metodologias de investigação ação participativa (IAP) recebem destaque, como é o caso do artigo de Guzmán Casado e Mielgo (2007). Os autores citam Fals Borda (1991) para explicar o objeto da IAP:

gerar um conhecimento libertador que parte do próprio conhecimento popular e que explica sua realidade globalmente (enfoque sistêmico), com o fim de iniciar ou consolidar uma estratégia de mudança (processos de transição), paralelamente a um crescimento do poder político, destinados ambos a alcançar transformaçóes positivas para a comunidade em nível local; e em níveis superior enquanto que é capaz de conectar-se com experiências similares (redes) (GUZMÁN CASADO e MIELGO, 2007, p. 30)

O fato de partir de conhecimento popular situa a participação dos agricultores no centro do processo de investigação, e garante a compreensão holística da realidade por parte do pesquisador. Citam como fases do processo que integram a IAP: a observação participante; a investigação participativa; a ação participante; a evolução.

Ainda no âmbito das pesquisas e com o objetivo de pontuar as redes que vem se constituindo em torno destas, Carvajal (2011) apresenta os programas vinculados as universidades latino-americanas que contemplam o tema agroecologia, fazendo-o por meio de distribuição geográfica, sendo que é perceptível uma concentração destes no México e Colômbia.

O autor (2011) também é partidário da utilização de metodologias participativas para construção do conhecimento agroecológico. Afirma em determinado momento do seu artigo que "a agroecologia como planejamento investigativo tem a premissa de ter uma formulação social, que se sustenta em movimentos participativos para a construção de conhecimentos a partir de experiências ancestrais ou princípios de coevolução social e ecológica. Também se propõe a geração de conhecimentos e métodos inovadores, e estratégias de recontextualização entre os conhecimentos ancestrais acumulados ao longo do tempo e a geração de novos conhecimentos”. (CARVAJAL, 2011, p. 133)

Fica perceptível assim que os rumos metodológicos das pesquisas envolvendo a agroecologia direcionam os pesquisadores para aplicação das metodologias participativas.

\section{Consideraçóes finais}

$\mathrm{Na}$ condição de estudo bibliométrico este artigo buscou medir a influência dos pesquisadores e periódicos na construção epistemológica do tema agroecologia, em especial 
quando relacionados a área de ciências humanas, o que permitiu ao final, traçar um perfil das publicaçôes que pode contribuir para produção de novos trabalhos.

A revisão das publicaçôes indica que as pesquisas relacionadas ao tema agroecologia encontram-se disseminadas em todas as regiôes do país. A maior parte das publicaçôes contudo, ainda ocorre na regiāo Sul, o que pode estar diretamente associado ao grande número de agricultores ecologistas nela localizados.

A análise qualitativa demonstrou que as percepçóes apresentadas pelos diversos autores sobre o tema demonstram uma certa uniformidade conceitual e epistemológica, o que pode ser oriundo das matrizes teóricas utilizadas, que na sua maioria são representadas pelos mesmo autores. Altieri e Caporal são os mais citados.

A maior parte dos artigos analisados contemplam discussóes teóricas, recebendo destaque os discursos em busca da identificação ou construção de uma base epistemológica para agroecologia e aqueles voltados para constituição das bases conceituais. Estudos de caso também aparecem em grande número.

Em relaçáo a indexação das revistas cabe salientar que a maior parte dos artigos publicados não atingiu os extratos superiores, sendo publicados em revistas B1 e B2, ou, ainda, em revistas não indexadas. Nenhum artigo foi publicado em revistas A1 e A2.

Sobre as possibilidades de avanços no campo da agroecologia e, em especial nas pesquisas da área de ciências humanas, compreende-se que os resultados demonstram ainda haver espaço para difusão das pesquisas na área agroecológica junto as universidades privadas, uma vez que estas aparecem de forma quase que inexpressiva quando verificado o vínculo institucional dos pesquisadores.

Também sobre os possíveis avanços verifica-se que apesar dos temas serem os mais transversais ainda existe espaço para publicaçóes relacionadas a sistematizaçáo das experiências e aos modelos metodológicos empregados para coleta de informaçóes, afora a Investigação Ação Participante - IAP não foram apresentadas outras metodologias de intervenção participativas com características inovadoras.

\section{Agradecimento}

Esta pesquisa está sendo desenvolvida com o apoio do CNPq por meio do Edital Universal 01/2016.

\section{Referências}

ALVES, Adilson Francelino; GUIVANT, Julia Silva. Redes e Interconexões: Desafios para a construção da agricultura sustentável. INTERthesis, Florianópolis, v. 7, n.1, p. 01-27, jan./jul., 2010

ASSIS, Renato Linhares de. Globalização, desenvolvimento sustentável e ação local: o caso da agricultura orgânica. Cadernos de Ciência \& Tecnologia, Brasília, v. 20, n. 1, p. 79 96, jan./abr., 2003 
- Desenvolvimento rural sustentável no Brasil: perspectivas a partir da integração de açôes públicas e privadas com base na agroecologia. Economia aplicada, Ribeirão Preto. v. 75 , p. $75-89$, jan./mar., 2006

BARBOZA, Luís Gabriel Antão; THOMÉ, Henrique Vitório; RATZ, Raquel Jackline; MORAES, Alice Jacobus. Para além do discurso ambientalista: percepçóes, práticas e perspectivas da agricultura agroecológica. Ambiência. Guarapuava. v.8, n.2, p. 389-401, mai/ago, 2012

Borsatto, Ricardo Serra; Do Carmo, Maristela Simoes. Agroecologia e sua epistemologia. Interciencia. Caracas, v. 37, n. 9, p. 711-716, 2012.

BRASIL. Decreto No 7.794, de 20 de agosto de 2012. Institui a Política Nacional de Agroecologia e Produçáo Orgânica (PNAPO). Disponível em <http://www.planalto. gov.br/ccivil_03/_ato2011-2014/2012/decreto/d7794.htm>, acesso em 24 de outubro de 2015

CANUTO, João Carlos. Mitos sobre Agroecologia. Cadernos de Agroecologia. Pelotas, Vol. 6, n. 2, dez, 2011

CAPORAL, Francisco Roberto; COSTABEBER, José Antônio. Agroecologia: enfoque científico e estratégico para apoiar o desenvolvimento rural sustentável. Porto Alegre: EMATER-RS/ASCAR, 2002

CAPORAL, Francisco Roberto; AZEVEDO, Edisio Oliveria de. (Org.) Princípios e Perspectivas da Agroecologia. Paraná: Instituto Federal do Paraná, 2011. Disponível em <https://wp.ufpel.edu.br/consagro/files/2012/03/CAPORAL-Francisco-RobertoAZEVEDO-Edisio-Oliveira-de-Princ\%C3\%ADpios-e-Perspectivas-da-Agroecologia.pdf>, acesso em 17 de julho de 2017

CARVAJAL, Jhon Jairo Monje. La Agroecología: Un marco de referencia para entender sus processos em la investigación y la práxis. Luna Azul. Menizales, N. 32, p. 128-134, enero-junio, 2011

CASADO, G.I. Guzmán; MIELGO, A.M. Alonso. La investigación participativa em agroecologia: una herramienta para el desarrollo sustentable. Ecosistemas. Madrid, N. 16, p. 24-36, enero, 2007

DIAS, Valéria da Veiga; SCHULTZ, Glauco; SCHUSTER, Marcelo da Silva; TALAMINI, Edson; RÉVILLION, Jean Philippe. O mercado de alimentos orgânicos: um panorama quantitativo e qualitativo das publicaçóes internacionais. Ambiente \& Sociedade. São Paulo, v. XVIII, n. 1, p. 161-182, jan/mar. 2015

DUVAL, Henrique Carmona; FERRANTE, Vera Botta; VALENCIO, Norma Felicidades Lopes da Silva. Produção de autoconsumo em assentamentos rurais: princípios da 
agricultura sustentável e desenvolvimento. Sociedade Brasileira de Economia, Administraçáo e Sociologia Rural, Araras, 2008

FERNANDES, Lúcio André de Oliveira; PASCUAL, Unai. Análise de eficiência da agricultura familiar agroecologista. Revista de la Red Iberoamericana de Economía Ecológica. Seropédica, Vol. 24, p. 221 - 233, 2015

GEHLEN, Ivaldo. Políticas Públicas e Desenvolvimento Social Rural. São Paulo em Perspectiva, São Paulo, v. 18, n. 02, p. 95-103, 2004.

MAPA. Cadastro Nacional de Produtores Orgânicos. Disponível em <http://www. agricultura.gov.br/assuntos/sustentabilidade/organicos/cadastro-nacional-produtoresorganicos>, acesso em 28 de fevereiro de 2018

MAPA. Alimentos orgânicos renderam R\$ 4 bilhóes a produtores brasileiros em 2018. Disponível em <http://www.agricultura.gov.br/noticias/mercado-brasileiro-deorganicos-fatura-r-4-bilhoes>, acesso em 06 de junho de 2019

MORAES, Roque; GALIAZZI, Maria do Carmo. Análise textual discursiva. Ijuí: Editora Unijui, 2015

SANTOS, Fernando Passos dos; CHALUB-MARTINS, Lila. Agroecologia, consumo sustentável e aprendizado coletivo no Brasil. Educaçáo e Pesquisa, São Paulo, v. 38, n. 2, p. 469-483, abr./jul., 2012

SAQUET, Marcos Aurélio. Agricultura camponesa e práticas (agro)ecológicas. Abordagem territorial histórica-crítica, relacional e pluridimensional. MERCATOR, Fortaleza, v. 13, n.2, p. 125-143, mai./ago., 2014

SOUZA, Luciano Ricardinho de Santana. A modernização conservadora da agricultura brasileira, agricultura familiar, agroecologia e pluriatividade: diferentes óticas de entendimento e de construção do espaço rural brasileiro. Cuaderno desarrolho rural Bogotá, Colômbia, v. 8 (67), p. 231-249, julio-diciembre, 2011

VARGAS, Daiane Loreto; FONTOURA, Andréia Furtado; WIZNIEWSKY, José Geraldo. Agroecologia: base da sustentabilidade dos agroecossistemas. Geografia Ensino \& Pesquisa, Santa Maria, v. 17, n.1, jan./abr. 2013. 